\title{
Suitable traverse ratios for step precision winding
}

\author{
Milind Vasudeo Koranne ${ }^{*}$ and Kuldeep Mhedu
}

\author{
*Correspondence: \\ milvako@yahoo.co.uk \\ Textile Engineering \\ Department, Faculty \\ of Technology \\ and Engineering, The \\ Maharaja Sayajirao University \\ of Baroda, Vadodara, Gujarat, \\ India
}

\begin{abstract}
Step precision winding produces a yarn package that is free from ribbon formation and marginal variation in coil angle. In open step precision winding, traverse ratios used during package build are such that the resultant package is open suitable for end user applications like warping and dyeing. It is always a critical task for a manufacturer of step precision yarn winding system to find values of traverse ratios which are open and definitely ribbon free without any appearance of diamonds or honeycomb. Traverse ratios used in any commercial step precision yarn winding system are not accessible to the user. The authors have carried out basic work of finding suitable open wind traverse ratios for step precision winding and have come out with a novel approach of "SAFE ZONES" for finding suitable open traverse ratios. This paper discusses this novel approach that is very useful for manufacturers of step precision winding systems.
\end{abstract}

Keywords: Traverse ratio, Ribbon formation, Diamond/honeycomb appearance, Safe zones

\section{Introduction}

Phenomenon of cross winding delivered yarn onto packages takes place on several yarn spinning/rewinding/processing machines. Among different modes of winding like random, precision and step precision winding, step precision winding offers distinct advantages. Step precision winding combines positive characteristics of random and precision winding to form a pattern free package with coil angle varying over a narrow range (Koranne 2013).

In step precision winding, package starts winding in precision mode with a non-pattern forming traverse ratio giving coil angle very close to desired. Upon winding, coil angle keeps on reducing. After some interval, when coil angle has decreased to some extent, traverse ratio is instantaneously shifted to a new lower value that will bring coil angle closer to desired mean value. On continuing winding, coil angle again decreases and after certain interval traverse ratio is again instantaneously shifted to a new a nonpattern forming value to restore mean coil angle. Thus, a step precision wound package is wound with several non-pattern forming traverse ratios that are decreased progressively in steps to build a package with coil angle varying over a narrow range.

For applications like dyeing, warping and weft supply packages for shuttleless looms, open wind traverse ratios are taken. Manufacturer of a winding system has to take

(c) 2016 Koranne and Mhedu. This article is distributed under the terms of the Creative Commons Attribution 4.0 International License (http://creativecommons.org/licenses/by/4.0/), which permits unrestricted use, distribution, and reproduction in any medium, provided you give appropriate credit to the original author(s) and the source, provide a link to the Creative Commons license, and indicate if changes were made. 
utmost care to select all traverse ratios that are open not giving "diamond" and/or "honeycomb appearance". To build a package with minimal variation of coil angle, traverse ratios taken during winding of entire package need to be sufficiently large in number closer to one another. With use of a few traverse ratios, coil angle varies over a wide range. At change over from one traverse ratio to next lower one; if coil angle variation is large, traverse length on package suddenly change from a higher to lower value that adversely affects appearance of side flanks of packages. This may be permissible for applications like assembly winding where close winding giving high package density (and thereby high yarn content on package) is of main importance. But for other applications like dyeing, warping and weft supply packages for shuttleless looms, it is always advantageous to have several non-pattern forming open wind traverse ratios (Koranne 2013).

Several patents are available on step precision winding (German Patent 1999, 1992; United States Patent 1987, 1995, 2000, 2002) but none exactly describe the procedure of finding out non-pattern forming open traverse ratios that are acceptable visually also from the point of view of diamond or honeycomb appearance. Traverse ratios selected for step precision winding on commercial winding systems are not accessible to the user of winding system.

In cross wound packages, yarn is laid in form of helices reversing at extremes. Traverse ratio (also known as winding ratio/crossing ratio) is an important parameter associated with cross wound packages that is defined as number of coils laid on the package in a double traverse. If traverse ratio is expressed in form of fraction $\mathrm{X} / \mathrm{Y}$ (with $\mathrm{X}$ and $\mathrm{Y}$ as natural numbers without any common factor except 1 ), $Y$ indicates number of double traverses after which yarn comes to same place. With a smaller value of Y, yarn comes to same place after fewer double traverses causing overlapping of yarn wraps one above the other forming undesirable ribbons (patterns). For example, a traverse ratio of $11 / 3$ would form ribbons as wraps of yarn after every three double traverses overlap on one another. Such ribbon forming number shall be termed as "nominal traverse ratio". To avoid ribbon formation, traverse ratio for winding should be incremented or decremented from 11/3 so that yarn is displaced at least equal to its diameter that would eliminate overlapping and lay yarn adjacent to one another giving "close wind". If number is taken such that the displacement of yarn is substantially more, say four times yarn diameter, it becomes "open wind". Such non-ribbon forming numbers derived from "nominal traverse ratios" shall be called as "actual traverse ratios".

For end user applications like dyeing, warping and shuttleless loom weft supply open wind traverse ratios are usually selected in which wraps of yarn are seen substantially away from one another forming an open package facilitating flow of dye liquor during package dyeing or allowing withdrawal of yarn without tension peaks or slough off.

It is very essential to find out methods to determine suitable traverse ratios for step precision winding when task of manufacture of a step precision winding system is undertaken. The study reported in this paper discusses a novel approach developed to find out several suitable open wind traverse ratios for step precision winding. The outcome of this paper is very useful for manufacturers desirous to develop open step precision winding systems.

It can be mathematically shown that pattern forming ratios lie very close to one another. Their interval depends upon package diameter. Winding a cylindrical package 
with traverse length of $150 \mathrm{~mm}$ for package diameter range of $45 \mathrm{~mm}$ to $200 \mathrm{~mm}$ at constant angle of $16^{\circ}$, traverse ratio decreases progressively between 7.4005 and 1.6651 from empty to full package. During this build up fractions between 1 and 11 occur 241 times where ribbon formation is most likely. If traverse ratio is selected as any of these numbers, there would be occurrence of ribbon formation. If a traverse ratio is selected nearer to any of these numbers, partial overriding of yarns wraps is caused that result into formation of ridges and hollows on package surface (called as honeycomb formation). Even if yarns are adequately apart, certain numbers as traverse ratio give appearance of diamond pattern on package. This is also regarded as unacceptable by the users. Figure 1 shows unacceptable packages (with honeycomb formation and diamond appearance) and an acceptable package. Apart from this, other fractions of number higher than this can also become unacceptable depending upon yarn linear density and package diameter. Therefore, finding a suitable traverse ratio is a critical job as problematic ratios lie closer to one another.

\section{Methods}

\section{Machine used to conduct trials}

The experimental work of verifying suitability of calculated traverse ratios was carried out on a three spindle laboratory model Peass make rewinding machine model UFLEX with propeller traverse (traverse stroke remains constant). The machine has one spindle for assembly winding and the other two are for soft package winding/rewinding of dyed packages. This machine allows package winding in two modes-(1) precision winding and (2) step precision winding.

Out of several methods attempted, suitable traverse ratio table could be derived from two methods for a range of coil angle for package diameter range of $69-200 \mathrm{~mm}$. This is reported in trial 1 and trial 2.

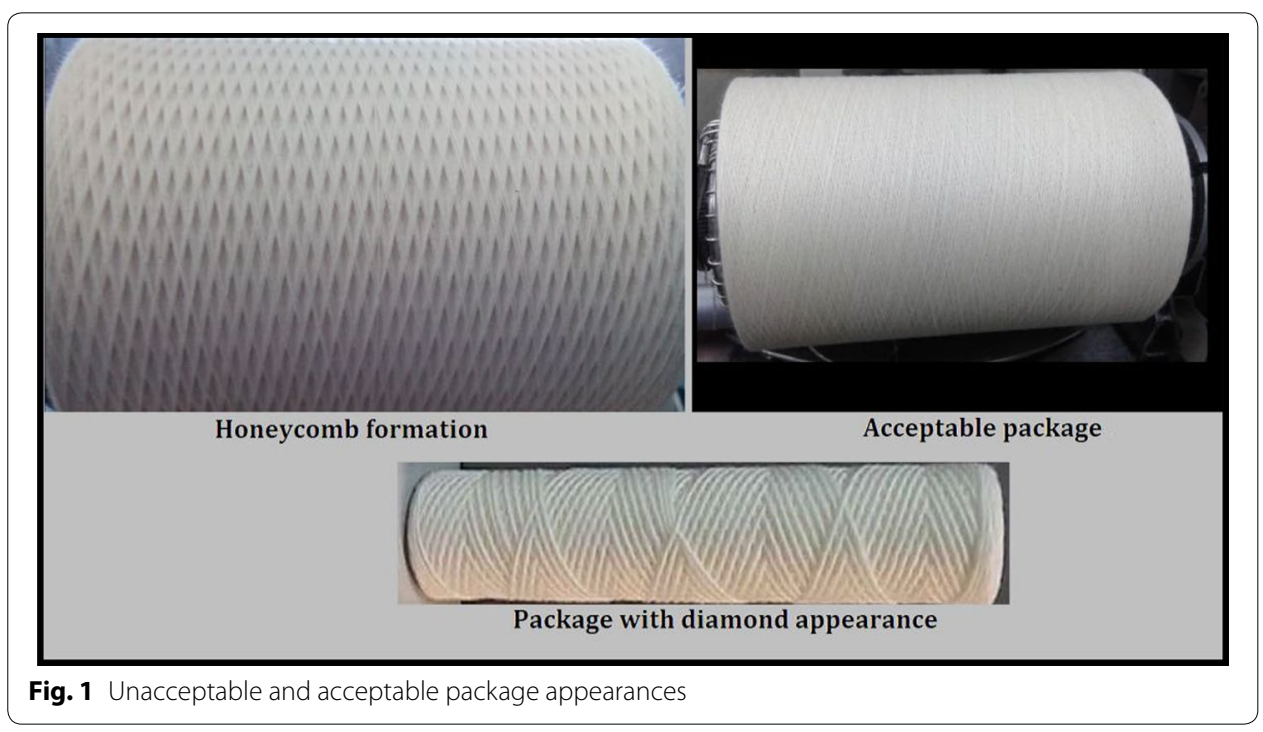


Trial 1

It is a common practice to find a suitable traverse ratio for precision winding from a traverse ratio that is prone to pattern formation (will be called as nominal traverse ratio and henceforth abbreviated as NTR) by giving some displacement to yarn at the end of pattern repeat. A head wind precision traverse ratio is a number little smaller than NTR where as an after wind precision traverse ratio is a number little larger than NTR. Using this method, a table was prepared with calculated traverse ratios from NTRs for fractions from 1 to 11 and a range of gain values from 2 to $5 \mathrm{~mm}$ (head as well as after wind). Trial was conducted on Peass UFlex rewinding machine to find its suitability. Suitability was assessed on visual basis (There is no defined test method to determine suitability of a traverse ratio. A number that did not give appearance of ribbons, diamond or honeycomb and yarns were seen adequately on actual winding trial was considered to be a suitable traverse ratio).

\section{Trial parameters were as follows}

Bare package diameter $69 \mathrm{~mm}$, Full package diameter $200 \mathrm{~mm}$, Winding speed $500 \mathrm{~m} /$ min, Yarn used $20 \mathrm{~s}$ Ne cotton yarn, Coil angle range $10^{\circ}-18^{\circ}$, Overfeed $15 \%$

For a given coil angle, suitable traverse ratios (among calculated traverse ratios) were found by practical run on machine. The machine permits input of traverse ratio up to four decimal points. To measure coil angle, photocopy of protractor was taken on a transparent plastic sheet. This sheet was put on package to measure angle at which yarn coils cross each other. Coil angle is half the crossing angle.

\section{Trial 2}

In the subsequent method of finding suitable traverse ratios, "SAFE ZONES" were identified logically where probability of pattern formation/honeycomb formation is minimized. It is known that for a traverse ratio expressed as a fraction $\mathrm{X} / \mathrm{Y}$ (with $\mathrm{X}$ and $\mathrm{Y}$ having no common factor except $1, \mathrm{Y}$ indicates number of double traverses after which yarn reaches the same point. With a smaller value of $Y$, yarn reaches same point after Y double traverses leading to pattern and/or honeycomb formation. A step precision wound package is built with a series of traverse ratios. Each traverse ratio is of the form, $Z \frac{A}{Y}$. Comparing this with form $X / Y, X=(Z \cdot A)+Y$. (For example, if $\mathrm{X}=78$ and $\mathrm{Y}=11$ fraction is 78/11. This fraction is $7 \frac{1}{11}$ when expressed as $\mathrm{Z} \frac{A}{Y}$. Here, $\mathrm{Z}=7, \mathrm{~A}=1$ and $\mathrm{Y}=11$. For a given package diameter, keeping same value of $A$ and $Y$, increasing value of $Z$ would decrease coil angle and vice versa. But yarn would come to the same place after 11 double traverses. Component $\frac{A}{Y}$ determines the distribution of yarn on the package circumference). All indivisible fractions up to 50 were arranged in decreasing order. Take a traverse ratio $\mathrm{Z} \frac{A}{Y}$, where $\mathrm{Z}$ is any positive integer (e.g. $0,1,2,3,4$ etc.) and $\frac{A}{Y}$ is any value among fractions of number 50 . Y gives us number of double traverses after which yarn reaches the same point. A smaller value of $Y$ would cause pattern and/or honeycomb formation. All numbers with values of $Y$ less than or equal to 20 were noted. A traverse ratio at or nearer to these numbers are expected to give pattern/diamond/honeycomb winding. Traverse ratios those are not nearer to any of these values are expected to give satisfactory winding. Traverse ratios within these zones only were considered for winding trial. Table 1 shows a part of indivisible fractions with denominator from 1 to 50 arranged in descending order where bolditalics highlighted fractions would give unsatisfactory winding (due to smaller 
Table 1 Some indivisible fractions with denominator from 1 to 50 arranged in descending order

\begin{tabular}{llllllllll}
\hline Sr. No. & Fractions $\frac{A}{Y}$ & Sr. No. & Fractions $\frac{A}{Y}$ & Sr. No. & Fractions $\frac{A}{Y}$ & Sr. No. & Fractions $\frac{A}{Y}$ & Sr. No. & Fractions $\frac{A}{Y}$ \\
\hline 1 & $\mathbf{1 9 / 2 0}$ & 8 & $47 / 50$ & 15 & $\mathbf{1 4 / 1 5}$ & 22 & $43 / 46$ & 29 & $37 / 40$ \\
2 & $37 / 39$ & 9 & $31 / 33$ & 16 & $41 / 44$ & 23 & $\mathbf{1 4 / 1 5}$ & 30 & $\mathbf{1 2 / 1 3}$ \\
3 & $\mathbf{1 8 / 1 9}$ & 10 & $46 / 49$ & 17 & $27 / 29$ & 24 & $41 / 44$ & 31 & $35 / 38$ \\
4 & $35 / 37$ & 11 & $\mathbf{1 5 / 1 6}$ & 18 & $40 / 43$ & 25 & $27 / 29$ & 32 & $23 / 25$ \\
5 & $\mathbf{1 7 / 1 8}$ & 12 & $44 / 47$ & 19 & $\mathbf{1 3 / 1 4}$ & 26 & $40 / 43$ & 33 & $34 / 37$ \\
6 & $33 / 35$ & 13 & $29 / 31$ & 20 & $38 / 41$ & 27 & $\mathbf{1 3 / 1 4}$ & 34 & $45 / 49$ \\
7 & $\mathbf{1 6 / 1 7}$ & 14 & $43 / 46$ & 21 & $25 / 27$ & 28 & $41 / 45$ & 35 & $\mathbf{1 1 / 1 2}$ \\
\hline
\end{tabular}

Bold italics most problematic zones, Italics probable "SAFE ZONES"

value of denominator) and the italics highlighted fractions become "SAFE ZONES" (as they are not very near to fractions with smaller value of denominator). A NTR is obtained by adding a positive integer to safe zone fraction. For example 44/47 and 29/31 are two consecutive safe zone fractions. Adding 9 to these fractions consecutive NTRs $9 \frac{44}{47}$ and $9 \frac{29}{31}$ are obtained. A suitable traverse ratio is expected to lie between these consecutive two NTRs. For a given coil angle, if very small displacement (like 0.4 or $0.6 \mathrm{~mm}$ ) is given to higher number of this pair, it is expected to get a suitable traverse ratio.

Trial was conducted to verify traverse ratios for step precision winding of cylindrical packages for different coil angles with empty package diameter $69 \mathrm{~mm}$, traverse length $150 \mathrm{~mm}$, full package diameter $200 \mathrm{~mm}$, over feed 10 to $25 \%$, and yarn tension $30 \mathrm{cN}$.

\section{Results and discussion}

Through trial 1, it became possible to develop a table for a particular coil angle for diameter range of 69-200 $\mathrm{mm}$ by selection among a large number of ratios; head and after wind from NTR of fractions up to 11 and yarn displacement ranging from 2 to $5 \mathrm{~mm}$. Such tables were developed for a range of coil angle.

A combination of a particular NTR and yarn displacement generates a suitable traverse ratio for a particular coil angle at specific diameter. Same combination of a particular NTR and yarn displacement may be suitable for other coil angle (that would be at different package diameter). A common table based on this logic for coil angle range of $10^{\circ}-14^{\circ}$ is developed. Table 2 shows a common table for $10^{\circ}-11^{\circ}$. Packages were step precision wound on Peass UFlex rewinding machine with these tables.

The outcome of this effort is summarised as:

It is possible to find suitable traverse ratios by this method through actual trial and error. This method is tedious and time consuming.

The interval of switch over from one traverse ratio to the other is around $3 \mathrm{~mm}$ over the entire package build except near whole numbers at some places. Suitable traverse ratios may be head wind or after wind.

The approach in trial 2 was more logical with theoretical base. Suitable traverse ratios were found for coil angle range of $10^{\circ}-14^{\circ}$ for bare package diameter of $69 \mathrm{~mm}$ to build packages up to $200 \mathrm{~mm}$ and different yarn displacements $(0.4,0.6$ and $0.8 \mathrm{~mm})$. The following is the results of the actual winding trial on Peass UFlex rewinding machine. 
Table 2 Common table for "Trial 1" section, coil angle range $10^{\circ}-11^{\circ}$

\begin{tabular}{|c|c|c|c|c|c|c|c|c|c|c|c|}
\hline \multirow[t]{2}{*}{ Sr.No. } & \multirow[t]{2}{*}{ NTR } & \multirow[t]{2}{*}{$\begin{array}{l}\text { Yarn disp. } \\
(\mathrm{mm})\end{array}$} & \multirow{2}{*}{$\begin{array}{l}\text { Actual } \\
\text { traverse } \\
\text { ratio }\end{array}$} & \multirow{2}{*}{\multicolumn{3}{|c|}{$\begin{array}{l}\text { Package diameterSr.No. } \\
\text { in } \mathrm{mm} \\
\text { For } 10^{\circ} \text { For } 11^{\circ}\end{array}$}} & \multirow[t]{2}{*}{ NTR } & \multirow{2}{*}{$\begin{array}{l}\text { Yarn } \\
\text { disp. } \\
(\mathrm{mm})\end{array}$} & \multirow{2}{*}{$\begin{array}{l}\text { Actual } \\
\text { traverse } \\
\text { ratio }\end{array}$} & \multicolumn{2}{|c|}{$\begin{array}{l}\text { Package diam- } \\
\text { eter in } \mathrm{mm}\end{array}$} \\
\hline & & & & & & & & & & For $10^{\circ}$ & For $11^{\circ}$ \\
\hline 1 & $77 / 9$ & -2 & 7.7719 & 69 & & 25 & $37 / 8$ & -2 & 3.8717 & 139.88 & 126.89 \\
\hline 2 & $75 / 9$ & -5 & 7.5413 & 71.81 & & 26 & $37 / 9$ & -4.5 & 3.7713 & 143.60 & 130.27 \\
\hline 3 & $71 / 8$ & 2 & 7.131 & 75.95 & 69 & 27 & $37 / 10$ & -2.5 & 3.6968 & 146.50 & 132.89 \\
\hline 4 & $610 / 11$ & -2.5 & 6.9038 & 78.44 & 71.16 & 28 & $33 / 5$ & -2 & 3.5951 & 150.64 & 136.65 \\
\hline 5 & $67 / 9$ & -2 & 6.7727 & 79.96 & 72.54 & 29 & $36 / 11$ & -2.5 & 3.5427 & 152.87 & 138.67 \\
\hline 6 & $62 / 3$ & 3.5 & 6.64 & 81.56 & 73.99 & 30 & $35 / 11$ & 3 & 3.4578 & 156.62 & 142.08 \\
\hline 7 & $63 / 7$ & 3 & 6.638 & 81.59 & 74.01 & 31 & $32 / 5$ & 4.5 & 3.4105 & 158.79 & 144.05 \\
\hline 8 & $62 / 9$ & 3 & 6.2293 & 86.94 & 78.86 & 32 & $31 / 3$ & -5 & 3.3143 & 163.40 & 148.23 \\
\hline 9 & 6 & -2.5 & 5.9486 & 91.04 & 82.59 & 33 & $33 / 11$ & 2 & 3.2748 & 165.37 & 150.01 \\
\hline 10 & $53 / 4$ & 2 & 5.7598 & 94.03 & 85.29 & 34 & $31 / 5$ & -2 & 3.1956 & 169.47 & 153.73 \\
\hline 11 & $53 / 5$ & -3.5 & 5.5866 & 96.94 & 87.94 & 35 & $31 / 8$ & -2.5 & 3.1217 & 173.48 & 157.37 \\
\hline 12 & 5 5/11 & -2 & 5.4511 & 99.35 & 90.12 & 36 & $31 / 9$ & 3 & 3.1147 & 173.87 & 157.73 \\
\hline 13 & $54 / 11$ & -5 & 5.3553 & 101.13 & 91.74 & 37 & $31 / 11$ & 2 & 3.0929 & 175.10 & 158.84 \\
\hline 14 & $51 / 10$ & 5 & 5.1087 & 106.01 & 96.16 & 38 & 3 & -2.5 & 2.9743 & 182.08 & 165.17 \\
\hline 15 & $49 / 10$ & 3.5 & 4.9059 & 110.39 & 100.14 & 39 & $29 / 10$ & -2 & 2.898 & 186.88 & 169.52 \\
\hline 16 & $46 / 7$ & 3.5 & 4.8655 & 111.31 & 100.97 & 40 & $29 / 11$ & 4.5 & 2.8221 & 191.90 & 174.08 \\
\hline 17 & $42 / 3$ & 3 & 4.6826 & 115.66 & 104.91 & 41 & $27 / 9$ & 2 & 2.7799 & 194.82 & 176.72 \\
\hline 18 & $44 / 7$ & 2.5 & 4.577 & 118.32 & 107.33 & 42 & $23 / 4$ & -3.5 & 2.7418 & 197.52 & 179.18 \\
\hline 19 & $43 / 7$ & -4 & 4.4199 & 122.53 & 111.15 & 43 & $25 / 7$ & 3.5 & 2.7189 & 200 & 180.69 \\
\hline 20 & $41 / 3$ & -4.5 & 4.3111 & 125.62 & 113.95 & 44 & $22 / 3$ & 3 & 2.6758 & & 183.60 \\
\hline 21 & $41 / 5$ & -2 & 4.1942 & 129.12 & 117.13 & 45 & $23 / 5$ & 4.5 & 2.608 & & 188.37 \\
\hline 22 & $41 / 8$ & -3.5 & 4.1188 & 131.49 & 119.27 & 46 & $26 / 11$ & -2 & 2.5439 & & 193.12 \\
\hline 23 & $41 / 9$ & -2 & 4.108 & 131.83 & 119.59 & 47 & $21 / 2$ & 2 & 2.5086 & & 195.83 \\
\hline 24 & 4 & 5 & 4.0685 & 133.11 & 120.75 & 48 & $25 / 11$ & -2 & 2.453 & & 200 \\
\hline
\end{tabular}

Number of attempts in searching suitable ratios greatly reduced.

The suitable traverse ratios derived from NTRs were with yarn displacement of $0.4 \mathrm{~mm}$. Search was begun first from the lowest angle i.e. $10^{\circ}$ and the suitable ratios were found. The traverse ratios those gave satisfactory winding for $10^{\circ}$ were also found suitable for subsequent next angle.

At smaller package diameter, NTRs with relatively smaller value of Y (between 20 and 25) lead to satisfactory winding giving suitable traverse ratios.

At subsequent diameters, satisfactory actual traverse ratios were obtained those are derived from nominal traverse with $\mathrm{Y}$ value lying between 30 and 45 barring few exceptions.

The interval of switch over from one traverse ratio to the other is around $2 \mathrm{~mm}$ over the entire package build except near whole numbers at some places. This interval increases at whole numbers especially at larger diameters due to non-availability of suitable traverse ratios.

Side flanks of packages were almost planar (as seen visually) due to shorter interval of change over from one traverse ratio to the other. Ring formation was not observed for $10^{\circ}-12^{\circ}$ coil angle. Ring formation is observed for $13^{\circ}$ and $14^{\circ}$ coil angle at around 195 and $189 \mathrm{~mm}$ package diameters respectively at traverse ratio transition region from 2 to 1. Figure 2 shows side faces of packages with $10^{\circ}$ and $14^{\circ}$. 


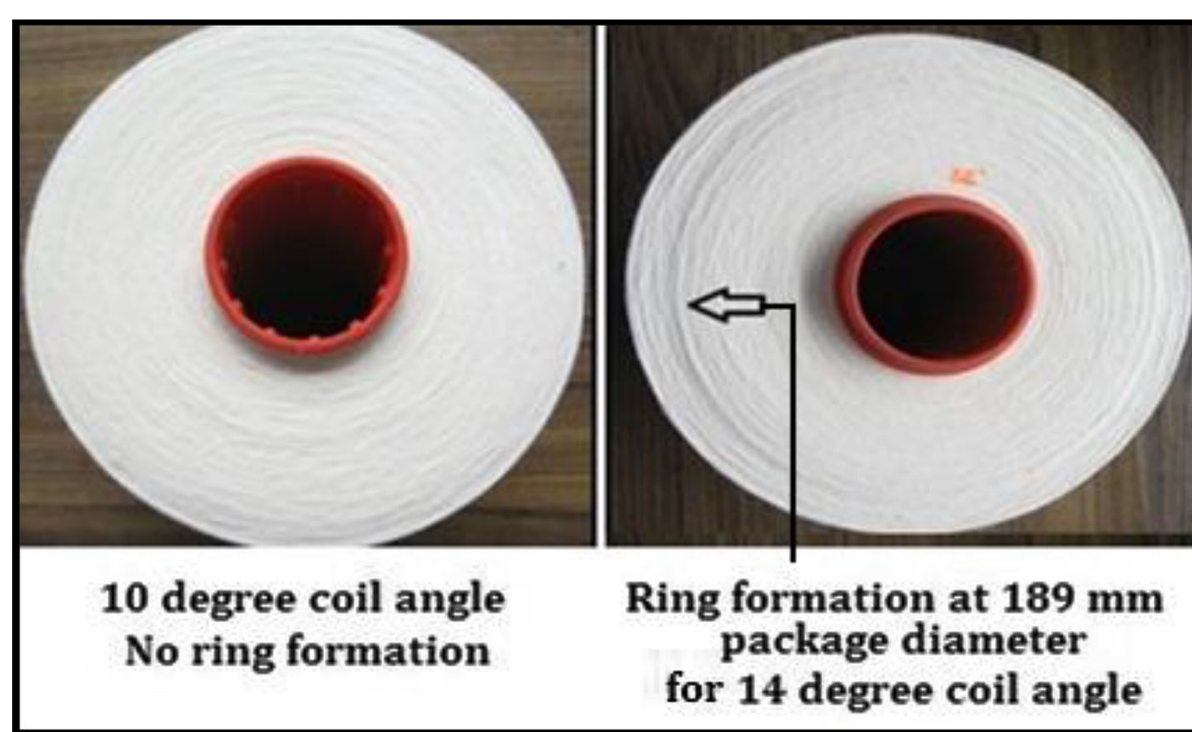

Fig. 2 Ring formation

The table developed was transferred to Peass UFlex rewinding machine through software and winding trials were conducted and packages for the entire range of coil angles were produced to confirm winding trial in continuous run.

Table 3 shows table for $10^{\circ}$ coil angle.

Table 3 Traverse ratio table for $10^{\circ}$, "Trial 2" section

\begin{tabular}{lllllllll}
\hline Sr. No. & $\begin{array}{l}\text { Traverse } \\
\text { ratios }\end{array}$ & $\begin{array}{l}\text { Diameter } \\
\text { for } \mathbf{1 0}^{\circ}\end{array}$ & Sr. No. & $\begin{array}{l}\text { Traverse } \\
\text { ratios }\end{array}$ & $\begin{array}{l}\text { Diameter } \\
\text { for } \mathbf{1 0}^{\circ}\end{array}$ & Sr. No. & $\begin{array}{l}\text { Traverse } \\
\text { ratios }\end{array}$ & $\begin{array}{l}\text { Diameter } \\
\text { for } \mathbf{1 0}^{\circ}\end{array}$ \\
\hline 1 & 7.8617 & 69 & 22 & 4.6561 & 116.31 & 43 & 3.3234 & 162.96 \\
2 & 7.6396 & 70.89 & 23 & 4.5674 & 118.57 & 44 & 3.2811 & 165.06 \\
3 & 7.4479 & 72.71 & 24 & 4.4410 & 121.95 & 45 & 3.2257 & 167.89 \\
4 & 7.3232 & 73.95 & 25 & 4.3609 & 124.19 & 46 & 3.1794 & 170.34 \\
5 & 7.1078 & 76.19 & 26 & 4.2811 & 126.50 & 47 & 3.1080 & 174.25 \\
6 & 6.8934 & 78.56 & 27 & 4.2186 & 128.38 & 48 & 3.0644 & 176.73 \\
7 & 6.7034 & 80.79 & 28 & 4.1387 & 130.85 & 49 & 3.0605 & 176.96 \\
8 & 6.4480 & 83.99 & 29 & 4.0809 & 132.71 & 50 & 3.0269 & 178.92 \\
9 & 6.2598 & 86.51 & 30 & 4.0643 & 133.25 & 51 & 2.9755 & 182.01 \\
10 & 6.1079 & 88.67 & 31 & 3.9399 & 137.46 & 52 & 2.9267 & 185.04 \\
11 & 5.8972 & 91.83 & 32 & 3.9061 & 138.65 & 53 & 2.8973 & 186.92 \\
12 & 5.7434 & 94.29 & 33 & 3.8610 & 140.27 & 54 & 2.8717 & 188.59 \\
13 & 5.6051 & 96.62 & 34 & 3.7940 & 142.74 & 55 & 2.8444 & 190.40 \\
14 & 5.4863 & 98.71 & 35 & 3.7574 & 144.13 & 56 & 2.8084 & 192.84 \\
15 & 5.3609 & 101.02 & 36 & 3.7095 & 145.99 & 57 & 2.7749 & 195.17 \\
16 & 5.2431 & 103.29 & 37 & 3.6332 & 149.06 & 58 & 2.7435 & 197.40 \\
17 & 5.1387 & 105.39 & 38 & 3.5860 & 151.02 & 59 & 2.7096 & 199.87 \\
18 & 5.0809 & 106.59 & 39 & 3.5142 & 154.11 & 60 & 3.3234 & 162.96 \\
19 & 4.9060 & 110.39 & 40 & 3.4826 & 155.51 & 61 & 3.2811 & 165.06 \\
20 & 4.7939 & 112.97 & 41 & 3.4410 & 157.38 & 62 & 3.2257 & 167.89 \\
21 & 4.7305 & 114.48 & 42 & 3.3822 & 160.12 & 63 & 2.6756 & 200 \\
\hline & & & & & & & &
\end{tabular}


Table 4 Range of variation of coil angle $10^{\circ}-14^{\circ}$ ("Trial $2^{\text {" section) }}$

\begin{tabular}{llll}
\hline Sr. No. & Degree & $\begin{array}{l}\text { Minimum variation in coil angle } \\
\text { in degree }\end{array}$ & $\begin{array}{l}\text { Minimum variation } \\
\text { in coil angle in degree }\end{array}$ \\
\hline 1 & $10^{\circ}$ & 0.01 & 0.57 \\
2 & $11^{\circ}$ & 0.01 & 0.52 \\
3 & $12^{\circ}$ & 0.01 & 0.53 \\
4 & $13^{\circ}$ & 0.02 & 0.57 \\
5 & $14^{\circ}$ & 0.02 & 0.55 \\
\hline
\end{tabular}

At each change over from one traverse ratio to the other, coil angle is restored back to the desired coil angle. On continuing winding, it decreases till change over to the other lower ratio. Range of decrease in coil angle for each angle is shown in Table 4.

\section{Conclusions}

This paper described the methods of finding open wind traverse ratios for step precision winding that give ribbon free winding without any diamond or honeycomb appearance. Based on fundamentals of yarn winding, "SAFE ZONES" were identified. It was found that suitable traverse ratios can be derived very conveniently within "SAFE ZONES". Traverse ratios were identified that are closer to one another. During transition from one whole number to the other, difficulties do arose in finding suitable traverse ratios especially during change in the region of change from traverse ratio 2 to 1 where the interval became wider resulting into ring formation for coil angles of $13^{\circ}$ and $14^{\circ}$. The variation in coil angle did not exceed $0.57^{\circ}$. The outcome of this work is very useful for manufacturers desirous to develop step precision winding systems.

Authors' contributions

MVK conceived and designed the experiments. KM performed the experiments, analyzed the data in consultation with MVK. All authors read and approved the final manuscript.

\section{Acknowledgements}

The authors would like to thank Peass Industrial Engineers Private Limited, Navasari, Gujarat, India for their help.

Competing interests

The authors declare that they have no competing interests.

Received: 7 September 2015 Accepted: 15 March 2016

Published online: 28 April 2016

\section{References}

Koranne, M. V. (2013). Fundamentals of yarn winding. New Delhi: Woodhead Publishing India Pvt Ltd.

German Patent No. 2649780 A1, 18 May 1977, Geli Dr Ing Specha, Wickelmaschine fuer textilgarne mit reibwalzenantrieb der kreuzspule.

German Patent No. 4037278, 1 Oct 1992, Heiner paelehstedt De kudrus, Ekkehard Nevmuenster De Schlueter, Guenter Dr. Hollenbek De Grabe, Verfahren zum aufspulen eines fadens in gestufter praezisionswicklung. United States Patent No. 4667889, May 26 1987, Siegmar Gerhartz, stepped precision winding proceSS. United Sates Patent No. 5447277, 5 Sept. 1995, Ekkehard Schliiter, Neumiinster and Heiner Kudrus, Barmstadt, Method of winding yarn on a bobbin or the like in a stepwise high precision winding process.

United States Patent No.6027060, 22 Feb. 2000, Peter Siepmann, method of winding a yarn to a cylindrical cross wound package.

United States Patent No. 6484962 B2, 26 Nov. 2002, Manfred Lassmann, method for graduated precision winding of a textile yarn cheese. 